\title{
REAGINDO A TEXTOS: INSTANCIAÇÕES DE GÊNERO TEXTUAL EM LIVROS DIDÁTICOS DE LÍNGUA PORTUGUESA ${ }^{1}$
}

\section{REACTING TO TEXTS: TEXTUAL GENRE INSTANTIATION IN PORTUGUESE LANGUAGE TEXTBOOKS}

\author{
Mhdi Ibrahim Bader Khun ${ }^{2}$ \\ Universidade Federal de Santa Maria (UFSM) \\ Cristiane Fuzer ${ }^{3}$ \\ Universidade Federal de Santa Maria (UFSM)
}

\section{RESUMO}

Este estudo objetiva investigar realizações linguísticas que instanciam gêneros de texto da família das reações a texto em textos nomeados como "crítica", presentes em livros didáticos de língua portuguesa dos ensinos fundamental e médio. Para isso, são mobilizados pressupostos teóricos acerca dos gêneros de texto da família de reações a texto (MARTIN; ROSE, 2008; CHRISTIE; DEREWIANKA, 2008), do sistema de Transitividade (HALLIDAY; MATTHIESSEN, 2014) e do subsistema atitude do sistema de Avaliatividade (MARTIN; WHITE, 2005), que permitem identificar as etapas de gênero de texto, bem como seu propósito sociocomunicativo específico. Os resultados evidenciaram que os textos analisados instanciam, na perspectiva sistêmicofuncional, os gêneros de texto resenha e interpretação temática.

PALAVRAS-CHAVE: Linguística Sistêmico-Funcional; Livro didático de Língua Portuguesa; Reações a texto; Resenha, Interpretação temática.

\section{ABSTRACT}

The aim of this study is to investigate the linguistics realizations which instantiate text genres of the text response family in texts named as "criticism", these texts are present in Portuguese language textbooks of primary and secondary education. In this regard, theoretical assumptions about genre of the family of text response (MARTIN; ROSE, 2008; CHRISTIE; DEREWIANKA, 2008), the Transitivity system (HALLIDAY; MATTHIESSEN, 2014) and the attitude subsystem of the Appraisal system (MARTIN; WHITE, 2005) are mobilized, with these theories it is possible to identify the text gender stages, as well as, its socio-communicative purpose. The results demonstrate that the analyzed texts instantiate, in the systemic function perspective, the text genres review and thematic interpretation.

KEYWORDS: Systemic Functional Linguistics; Portuguese Language Textbook; Text response; Review; Thematic interpretation.

\section{INTRODUÇÃO}

Desde a ascensão da Linguística Aplicada no Brasil, em meados da década de 1960, diversos estudos têm revelado novas concepções do que são gêneros do discurso/texto. Isso tem refletido no contexto escolar, especificamente nos livros didáticos de língua portuguesa (LDLP)

\footnotetext{
${ }^{1}$ O presente trabalho foi realizado com apoio da Coordenação de Aperfeiçoamento de Pessoal de Nível Superior Brasil (CAPES) - Código de Financiamento 001 -, e é parte dos resultados obtidos na pesquisa de mestrado, em andamento, do primeiro autor, com a orientação da segunda autora.

${ }^{2}$ Licenciado em Letras - Português e Literaturas EaD pela Universidade Federal de Santa Maria (UFSM) e mestrando em Letras - Estudos Linguísticos pela mesma universidade. Email: baderkhun@outlook.com

3 Professora Associada do Departamento de Letras Vernáculas e do Programa de Pós-Graduação em Letras da Universidade Federal de Santa Maria (UFSM). Doutora em Letras. Email: crisfuzerufsm@gmail.com
} 
que, segundo os Parâmetros Curriculares Nacionais (BRASIL, 1998), é um dos instrumentos responsáveis pelo trabalho com diferentes textos orais e escritos. Como os LDLP distribuídos nas escolas podem ser usados como norteadores de atividades de leitura, análise linguística e produção textual em sala de aula, torna-se importante olhar com mais atenção para os textos selecionados e disponibilizados nesses materiais.

A partir disso, diversos estudos sobre gêneros em LDLP têm sido desenvolvidos em diferentes perspectivas. O estudo de Melo (2015), por exemplo, ancorado na perspectiva do Interacionismo Sócio-Discursivo, analisa o trabalho com textos argumentativos nos LDLP Português Linguagens - Volume 1, de Cereja e Magalhães (2013b), e Português - Vozes do mundo 1: literatura, língua e produção de texto, de Campos et al. (2013), e constata que apenas o segundo apresenta uma proposta teórico-metodológica adequada à perspectiva. Outro exemplo é o estudo de Nascimento (2016) que, a partir da perspectiva dialógica de Bakhtin, analisa os gêneros e as atividades propostas no LDLP Português linguagens - Volume 3, de Cereja e Magalhães (2013d), e conclui que essas atividades não são insuficientes para esclarecer aos alunos a intrínseca relação entre gênero e especificidades estilísticas, além de trazer dissonâncias entre diferentes abordagens, apresentando ora gêneros do discurso, ora gêneros textuais.

$\mathrm{Na}$ perspectiva da Linguística Sistêmico-Funcional (LSF), principiada por Halliday (1985b) e expandida por seus seguidores (MARTIN, 1992; EGGINS, 1994; THOMPSON, 2004, entre outros), também há trabalhos dessa natureza. Como exemplo, cita-se o estudo de Gerhardt (2017) que analisa as instanciações dos gêneros de texto episódio e exemplum - da família das estórias - nos dois LDLP mais distribuídos pelo Plano Nacional do Livro Didático (PNLD) para o triênio 2014-2016 e apura que esses gêneros de texto são mais utilizados em atividades que envolvem conteúdo do estrato léxico-gramatical, como morfologia e sintaxe, do que em atividades que contemplem conteúdo do estrato semântico-discursivo, como discurso direito e indireto. Soares (2018) também investigou gêneros de texto da família das estórias em contos e crônicas extraídos dos três volumes da coleção LDLP Português Linguagens para o ensino médio, de Cereja e Magalhães (2013b,2013c, 2013d), e da internet, e comprovou que a supressão de partes do texto (etapas e fases) pode ocasionar mudança de gênero de texto. Esse estudo aponta também que, em sua maioria, os contos analisados instanciam o gênero de texto observação, e as crônicas o gênero de texto Relato.

$\mathrm{Na}$ perspectiva sistêmico-funcional, gêneros de texto são definidos como "processos sociais organizados por etapas e orientados para propósitos sociais" "MARTIN; ROSE, 2008, p.08). Ou seja, gêneros de texto são construídos pelos falantes/ouvintes para um determinado público a fim de alcançarem propósitos sociocomunicativos e organizados em etapas pelo fato de ser necessário mais de um passo até que os propósitos sejam alcançados. Mediante análise das realizações linguísticas, podemos identificar a Estrutura Esquemática de Gênero (EEG) organizada em etapas, bem como o propósito sociocomunicativo específico, que permite aos analistas concluírem se textos são ou não semelhantes e, também, se são diferentes gêneros de texto (EGGINS; MARTIN, 1997).

Partindo desses pressupostos teóricos da LSF, esta investigação também lança seu olhar sobre textos presentes em LDLP. Mais precisamente, o presente estudo tem como objetivo investigar realizações linguísticas que instanciam gêneros de texto da família de reações a texto em textos nomeados como "crítica", presentes em livros didáticos de língua portuguesa dos ensinos fundamental e médio.

Para isso, nas seções a seguir, são apresentados conceitos fundamentais da LSF, que permitem situar as reações a texto nos estudos da perspectiva. Também são apresentados o sistema léxico-gramatical de Transitividade (HALLIDAY; MATTHIESSEN, 2014) e o subsistema atitude do sistema semântico-discursivo de Avaliatividade (MARTIN; WHITE (2005), que embasam as análises empreendidas neste artigo. Em seguida, a metodologia adotada

\footnotetext{
4 Tradução nossa de "genre as a staged goal-oriented social process."
} 
neste estudo, sequente das análises que evidenciam os resultados. Por fim, as considerações finais, onde são retomados os resultados, e apresentadas reflexões surgidas a partir deste estudo, uma vez que os textos analisados são utilizados em atividades de ensino de produção de textos em diferentes níveis escolares: $8^{\circ}$ ano do ensino fundamental e $3^{\circ}$ ano do ensino médio.

\section{Linguística Sistêmico-Funcional}

$\mathrm{Na}$ LSF, a linguagem é concebida como uma prática social e desenvolveu-se para satisfazer necessidades humanas em contextos específicos (HALLIDAY, 1985). Nessa perspectiva, a linguagem é um sistema sociossemiótico que oferece opções de escolha para os falantes utilizarem em determinados contextos (HALLIDAY; MATTHIESSEN, 2014). Tal relação intrínseca entre língua e contexto forma um sistema complexo, conforme ilustra a Figura 1, numa relação de realização entre seus respectivos estratos: o estrato da fonologia e grafologia realiza o estrato da léxico-gramática, que realiza o estrato da semântica; esses, por sua vez, realizam o estrato do contexto (de situação e cultura) (HALLIDAY; MATTHIESSEN, 2014).

A partir da base teórica hallidayana, Martin (1992; 1997) e Martin e Eggins (1997) associam o contexto de cultura à noção de gênero textual, e Martin e Rose (2007) associam o discurso à semântica (Figura 1).

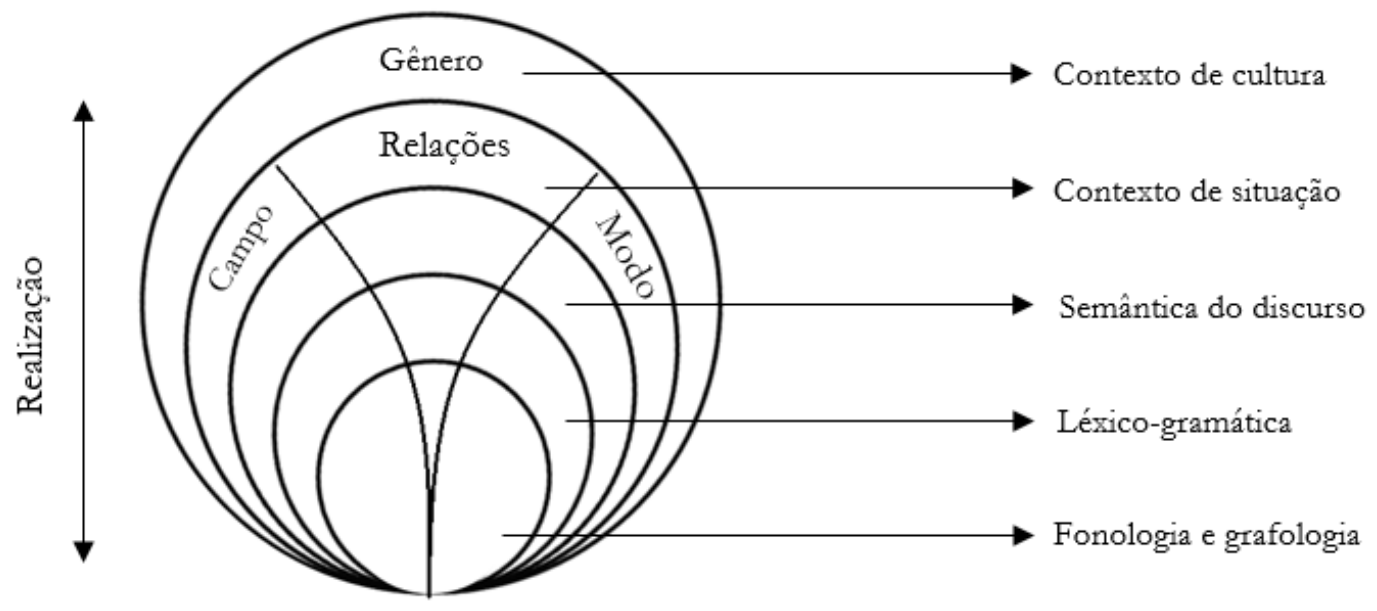

Figura 1 - Linguagem organizada em estratos (MARTIN, 1997)

Os estratos mostrados na Figura 1 são organizados de acordo com o nível de abstração de suas redes de sistemas. Cada estrato é modelado por três grandes significados denominados por Halliday (1985a) como metafunções: ideacional (concernente a representação das experiências), interpessoal (concernente a interação de participantes) e textual (concernente a organização da mensagem).

No estrato da fonologia e da grafologia, estão os sistemas de sons e escrita (HALLIDAY; MATTHIESSEN, 2014). No estrato da léxico-gramática, estão concentrados os sistemas de construção de significados em orações ou unidades menores: os sistemas de Transitividade e Ergatividade na metafunção ideacional; MODO, polaridade e modalidade na metafunção interpessoal, e Estrutura temática e Estrutura da informação na metafunção textual (HALLIDAY; MATTHIESSEN, 2014). Na construção de significados para além da oração, no estrato da semântica do discurso, estão os sistemas de Ideação e Conjunção (metafunção ideacional), Avaliatividade e Negociação (metafunção interpessoal) e Periodicidade e Identificação (metafunção textual) (MARTIN; ROSE, 2007).

Acima dos estratos da língua, estão os estratos do contexto social (HALLIDAY; MATTHIESSEN, 2014), compreendendo os níveis de registro e gênero textual (EGGINS; 
MARTIN, 1997). Os significados dos estratos linguísticos projetam uma relação de metarredundância (LEMKE, 1995) com as variáveis do contexto de situação: campo (concernente às atividades que ocorrem) com metafunção ideacional, relações (concernente às interações) com metafunção interpessoal, e modo (concernente ao veículo utilizado e ao papel da linguagem) com metafunção textual (HALLIDAY, 1985). Essas variáveis, juntas, formam o registro, que é, de acordo com Eggins e Martin (1997, p. 340), "uma explicação teórica da observação do sentido comum que indica como usamos a linguagem em diferentes modos em situações diferentes."

Os modos de uso da linguagem configuram os textos que se desdobram, por meio de uma EEG, para atingir seu propósito sociocomunicativo específico (EGGINS; MARTIN, 1997). Desta forma, os estudos de gênero de texto na LSF buscam compreender como os indivíduos usam a linguagem em determinada cultura (MARTIN; ROSE, 2008), instanciando esse uso a fim de atingir propósitos sociocomunicativos.

\subsection{Gêneros de texto da família das reações a texto}

Desde a década de 1980, pesquisadores australianos em LSF vêm desenvolvendo programas de letramento com base em gêneros de texto, também conhecidos como Pedagogia de Gêneros da Escola de Sydney. Nesses programas, os pesquisadores, preocupados com a proficiência dos alunos, descreveram a EEG e os propósitos sociocomunicativos dos textos que os alunos precisam ler e escrever durante a educação primária e secundária, em todas as disciplinas do currículo (ROSE; MARTIN, 2012).

Como resultado dessa descrição, os pesquisadores conseguiram agrupar os gêneros de texto em famílias, de acordo com propósito sociocomunicativo que lhes era particular (ROSE; MARTIN, 2012). Em seguida, as famílias de gêneros de texto foram reunidas em três grandes grupos, de acordo com seu propósito sociocomunicativo geral, o qual todas as famílias dentro desse grande grupo compartilham, quais sejam: envolver, informar e avaliar.

Dentre as famílias de gêneros de texto com o propósito sociocomunicativo de avaliar, estão a família dos argumentos e das reações a texto. De acordo com Rose e Martin (2012), gêneros de texto da família dos argumentos fazem amplo uso do sistema de Avaliatividade para persuadir os leitores/ouvintes. Reações a texto também fazem amplo uso do sistema de Avaliatividade, mais especificamente do subsistema atitude, mas com um propósito diferente: criticar outros textos ${ }^{6}$. Segundo Martin e Rose (2008), quatro são os gêneros de texto da família de reações a texto: resposta pessoal (personal response), resenha (review), interpretação (interpretation) e resposta crítica (critical response).

O gênero de texto resposta pessoal (personal response) apresenta EEG constituída da etapa ${ }^{7}$ Julgamento, na qual o crítico faz amplo uso de avaliações de atitude do campo semântico afeto, o que evidencia o propósito sociocomunicativo específico, que é expressar sentimentos sobre um texto (MARTIN; ROSE, 2008).

O gênero de texto resenha (review) tem como propósito sociocomunicativo específico avaliar um texto, e sua EEG é constituída das etapas Contexto, Descrição e Julgamento (MARTIN; ROSE, 2008). Na etapa Contexto, há informações sobre o texto (se é um romance, um jogo ou um filme); na etapa Descrição, há a apresentação de personagens (no caso de um jogo, livro ou filme) e alguns detalhes sobre o enredo do texto; na etapa Julgamento do texto, o texto é avaliado (MARTIN; ROSE, 2008).

\footnotetext{
5 Tradução nossa de "The theoretical explanation of the observation of the common-sense observation that we use language differently ways in different situations."

${ }^{6}$ Segundo Ferreira (2010, p.114), criticar é "fazer uma análise; salientando as qualidade(s) e/ou defeito(s) de algo, ou de alguém, ou de alguma coisa.

7 Por convenção da teoria, os nomes das etapas de gênero de texto são grafadas com inicial maiúscula.
} 
Com o propósito sociocomunicativo específico de interpretar a mensagem de um texto, o gênero de texto interpretação (interpretation) apresenta EEG constituída da etapa Avaliação, na qual o texto é avaliado e a mensagem do texto é apresentada; etapa Sinopse, em que certos elementos do filme são selecionados para ilustrar a mensagem, e etapa Reafirmação, na qual o texto é novamente avaliado e a mensagem elaborada (MARTIN; ROSE, 2008).

O gênero de texto resposta crítica (personal response), que tem o propósito sociocomunicativo específico de desafiar a mensagem de um texto, apresenta a EEG constituída da etapa Avaliação, na qual o texto é avaliado e é sugerida a possibilidade de desafio; etapa Desconstrução, na qual é mostrado como a mensagem do texto é construída, e etapa Desafio, na qual a mensagem é desnaturalizada.

Em estudos posteriores acerca das reações a texto, Christie e Derewianka (2008) descreveram dois novos gêneros de texto: análise de personagem (character analisys) e interpretação temática (thematic interpretation). A análise de personagens (character analisys), que tem o propósito sociocomunicativo específico de avaliar personagens de um texto, constitui-se das seguintes etapas: Apresentação das personagens, na qual a personagem a ser avaliada é apresentada; Descrição da personagem, em que a personagem é descrita e, por fim, a etapa Avaliação da personagem, na qual a personagem apresentada e descrita é avaliada (CHRISTIE e DEREWIANKA, 2008).

No que diz respeito à interpretação temática (thematic interpretation), que tem o propósito sociocomunicativo específico de avaliar elementos de um texto, o gênero de texto é constituído das seguintes etapas: na Apresentação dos elementos, são apresentados o tema a ser discutido e os elementos a serem avaliados na etapa posterior, que é a etapa Avaliação dos elementos; na etapa Reiteração do Tema, o tema é reiterado (CHRISTIE; DEREWIANKA, 2008).

\subsection{A gramática experiencial da oração, do grupo e das palavras}

Situado no estrato da léxico-gramática e responsável pela realização da metafunção ideacional experiencial, o sistema de Transitividade ocupa-se da representação das experiências em textos (HALLIDAY; MATTHIESSEN, 2014). Esse sistema, cuja instanciação acontece no nível da oração, configura-se em processos (tipicamente constituídos por grupos verbais), participantes (tipicamente constituídos por grupos nominais) e circunstâncias (tipicamente constituído por grupos adverbiais e sintagmas preposicionais). Os grupos, por sua vez, são constituídos palavras que desempenham funções experienciais: dêiticos, numeradores, epítetos, classificadores e qualificadores (HALLIDAY; MATTHIESSEN, 2014).

O sistema de Transitividade, descrito por Halliday (1985) e Halliday e Matthiessen (2014), envolve seis tipos de processos: materiais, mentais, relacionais, verbais, comportamentais e existenciais. Cada tipo de processo envolve determinados tipos de participantes: Ator, Meta, Escopo, Recebedor, Cliente, Atributo em orações com processos materiais; Experienciador e Fenômeno em orações com processos mentais; Portador e Atributo ou Identificador e Identificado em orações com processos relacionais. Já as orações com processos verbais, os participantes são Dizente, Verbiagem, Receptor e Alvo. Em orações com processos comportamentais, os participantes podem ser Comportante e Comportamento; em orações com processos existenciais, o único participante é o Existente (HALLIDAY; MATTHIESSEN, 2014).

Juntamente aos participantes e processos, circunstâncias podem, ou não, compor as orações. De acordo com Halliday e Matthiessen (2014), circunstâncias podem indicar extensão (distância, duração e frequência), localização (lugar e tempo), modo (meio, qualidade, comparação e grau), causa (razão, propósito e interesse), contingência (condição, falta, concessão), acompanhamento (comitativo e aditivo), papel (estilo, produto), assunto e ângulo (recurso e ponto de vista). 


\subsection{Subsistema atitude do sistema de Avaliatividade}

A atitude é um dos três subsistemas que compõem o sistema de Avaliatividade proposto por Martin e White (2005), que é um dos sistemas situados no estrato da semântica do discurso e associados à metafunção interpessoal (MARTIN; ROSE, 2007). Composto pelos campos semânticos de afeto, julgamento e apreciação, a atitude ocupa-se em avaliar coisas, pessoas e eventos por meio de reações emocionais e juízos de valor acerca do comportamento das pessoas e da estética, de forma positiva ou negativa (MARTIN; WHITE, 2005).

O campo semântico do afeto, de acordo com Martin e White (2005), ocupa-se dos recursos avaliativos referentes à emoção, expressando os sentimentos do falante/escritor em relação a coisas, pessoas e eventos. Esse campo semântico constitui-se de três significados avaliativos: felicidade/infelicidade (concernente às emoções do coração), segurança/insegurança (concernente ao bem-estar social) e satisfação/insatisfação (concernente à objetivos alcançados) (MARTIN; WHITE, 2005).

Avaliando comportamentos humanos, o campo semântico julgamento constitui-se de dois significados: estima social (concernente à admiração ou crítica) e sanção social (concernente a elogios ou condenação) (IEDEMA; et. al., (1994); MARTIN; WHITE, 2005). As avaliações de estima social podem ser de três tipos: normalidade (o quão especial o comportamento é), capacidade (o quão capaz a pessoa avaliada é) e tenacidade (o quão dependente o avaliado é). (MARTIN, WHITE, 2005). As avaliações de sanção social, de dois tipos: veracidade (o quão honesto o avaliado é) e propriedade (o quão ético é o avaliado)

Já o campo semântico apreciação, de acordo com Martin e White (2005), ocupa-se dos recursos avaliativos referentes à estética de coisas, pessoas, objetos, eventos, etc. Avaliações desse campo semântico podem ser de três significados distintos: reação (que pode indicar o impacto que a estética causa no avaliador ou a qualidade que as coisas possuem), composição (que pode indicar a opinião do avaliador em relação proporção ou complexidade do avaliado) e valoração (que indica a avaliação do significado social do avaliado) (MARTIN; WHITE, 2005).

\section{Metodologia}

Neste estudo, como primeiro critério, estabeleceu-se que os textos seriam selecionados dos LDLP mais distribuídos para cada ano dos ensinos fundamental $\left(6^{\circ}, 7^{\circ}, 8^{\circ}\right.$ e $9^{\circ}$ ano $)$ e médio $\left(1^{\circ}, 2^{\circ}\right.$ e $3^{\circ}$ ano), de acordo com os últimos dados estatísticos fornecidos pelo Fundo Nacional de Desenvolvimento da Educação (FNDE, 2018) ${ }^{8}$. Como segundo critério, para serem selecionados, os textos deveriam ser utilizados, no LDLP, em atividades de ensino de produção textual.

A partir disso, chamou-nos a atenção que, nos LDLP Português linguagens $-8^{\circ}$ ano (CEREJA; MAGALHÃES, 2013a) e Português linguagens - Volume 2 (CEREJA; MAGALHÃES, 2013c), há uma seção destinada ao ensino de produção de texto, em que o gênero denominado pelos autores do livro como "crítica" é o objeto a ser ensinado". Pelo fato de os textos dessa seção receberem a mesma denominação em ambos os LDLP, resolvemos analisa-los na perspectiva da LSF, para verificar se as realizações linguísticas instanciam esses textos em um mesmo gênero de texto.

Como terceiro critério de seleção, estabeleceu-se que seriam analisados apenas os textos que estivessem na íntegra, ou seja, sem omissão de trechos. Para isso, foi verificada a fonte indicada no LDLP, para confirmar se o texto se apresentava completo no LDLP.

\footnotetext{
${ }^{8}$ De acordo com o FNDE, a coleção Português linguagens, publicado pela editora Saraiva, foi a mais distribuída em todos os anos do ensino fundamental, no PNLD 2017-2019, e do ensino médio, no PNLD 2015-2017.

${ }^{9}$ Não é objetivo deste trabalho discutir a perspectiva teórica de gênero que norteia a coleção, e sim analisar os textos na perspectiva da LSF.
} 
Estabelecidos os critérios, a seleção resultou em uma amostra formada por dois textos: um presente no LDLP do $8^{\circ}$ ano do ensino fundamental, intitulado "Um time show de bola", e o outro, denominado "Filme propõe um olhar amoroso, mas não idealizado", presente no livro didático do $2^{\circ}$ ano do ensino médio. O primeiro é de autoria de Marcelo Hussel e publicado no site Omelete, no dia 28 de novembro de 2013; o segundo é de autoria de Luiz Zanin Oricchio, publicado no jornal O estado de São Paulo, no dia 05 de abril de 2012.

Para análise os textos, foram seguidos estes procedimentos: i) segmentação dos textos em orações; ii) análise de significados ideacionais com base no sistema de Transitividade; iii) análise de significados interpessoais com base no subsistema atitude do sistema de Avaliatividade; iv) identificação da EEG organizada em etapas e do propósito sociocomunicativo específico.

$\mathrm{Na}$ seção a seguir, para melhor identificação, a segmentação do texto em orações é sinalizada pelo símbolo || e orações encaixadas ${ }^{10}$ são sinalizadas entre os símbolos [[ ]] (entre colchetes duplos). Já as avaliações do subsistema atitude são sinalizadas em negrito, e a EEG é apresentada numa sequência de etapas, em que o símbolo ^ significa "seguida de".

\section{Análise e discussão dos resultados}

Com base nas análises do sistema de Transitividade e do subsistema atitude do sistema de Avaliatividade, foi possível evidenciar que os dois textos analisados neste estudo instanciam, cada um, um gênero de texto diferente. Nas subseções a seguir, são apresentadas as análises que permitem evidenciar a EEG de cada texto selecionado, organizada em etapas, bem como o propósito sociocomunicativo específico e, por conseguinte, o gênero de texto instanciado em cada um dos textos.

\subsection{Instanciação do gênero de texto resenha no texto intitulado Um time show de bola}

As análises do texto utilizado em atividades de produção textual no LDLP do $8^{\circ}$ ano do ensino fundamental evidenciaram a instanciação do gênero de texto resenha, com a EEG organizada nas etapas Contexto ${ }^{\wedge}$ Descrição ${ }^{\wedge}$ Julgamento. A seguir, são apresentadas as análises que evidenciam a realização dessas etapas.

\subsubsection{Etapa Contexto}

$\mathrm{Na}$ etapa Contexto, o autor do texto utiliza três tipos diferentes de orações: mental, relacional e material.

O cinema de nostalgia do diretor argentino Juan José Campanella aceita prontamente o futebol como tema, | | porque boa parte do mundo da bola vive do memorialismo - o velho terrão e a bola de meia versus o profissionalismo dos craques cosmopolitas e seus megaempresários - || da mesma forma que filmes como O Filho da Noiva e Clube da Lua são respostas de Campanella à crise financeira [[que tirou da Argentina a ilusão da bonança dos tempos do menemismo]].

Iniciando a etapa Contexto, a oração mental "O cinema de nostalgia do diretor argentino Juan José Campanella aceita prontamente o futebol como tema" introduz informações fundamentais ao(s) leitor(es): sobre a obra que será resenhada, quem é o diretor do filme e qual é o tema desse filme que, nessa etapa, ainda não é identificado (isso ocorre na etapa Descrição).

$\mathrm{Na}$ função léxico-gramatical de Experienciador, o grupo nominal " $\mathrm{O}$ cinema de nostalgia" indica que o texto resenhado é um filme. Em seguida, na escolha do qualificador "do

${ }_{10}$ De acordo com Halliday e Matthiessen (2014), orações encaixadas não tem status de oração e sim de grupo nominal. 
diretor argentino Juan José Campanella", há a indicação do diretor do filme, que é um dos mais famosos do cinema argentino. Depois do processo "aceita", o Fenômeno "futebol" e o Identificador "como tema" informam ao leitor a temática do filme.

Em seguida, por meio da oração relacional "boa parte do mundo da bola vive do memorialismo", o autor explica o motivo pelo qual o diretor escolheu o futebol, uma vez que, na opinião do autor, os filmes de Juan Campanella são memorialistas, assim como os filmes "O Filho da Noiva" e "Clube da Lua", grupos nominais que exercem função léxico-gramatical de Portador na oração relacional "filmes como O Filho da Noiva e Clube da Lua são respostas de Campanella à crise financeira”. Encaixada a essa oração relacional, mais especificamente ao grupo preposicional "à crise financeira", a oração material "que tirou da Argentina a ilusão da bonança dos tempos do menemismo" explica que crise financeira é essa.

\subsubsection{Etapa Descrição}

$\mathrm{Na}$ etapa Descrição, que segue a etapa Contexto, há a realização de orações mentais e relacionais, seguidas da realização de orações materiais e uma ocorrência de oração existencial. Essas orações indicam o lugar onde o enredo acontece e seus detalhes, bem como apresenta as personagens principais e suas características:

No início da animação Um Time Show de Bola (Metegol), parece || que estamos num bairro tradicional de Buenos Aires, parecido com o de O Filho da Noiva, em um daqueles cafés antigos com janela de vitrais na porta. || Lá dentro há uma mesa de pebolim (ou totó, ou fla-flu...), ||cujo campeão inconteste é o jovem introvertido Amadeo. | Anos depois de derrotar no jogo o garoto mais metido da vizinhança, || Amadeo vê o rival retornar à cidade, agora como um astro mundial do futebol de campo ||determinado a destruir o café e a mesa de pebolim e || construir no lugar um gigantesco estádio para uso próprio.

A etapa Descrição inicia com a oração mental "No início da animação Um Time Show de Bola (Metegol), parece que estamos num bairro tradicional de Buenos Aires", na qual o nome do filme que está sendo resenhado é informado por meio da circunstância de localização "No início da animação Um Time Show de Bola (Metegol)". Em seguida, depois do processo "parece", o cenário do filme é representado por meio de duas orações relacionais: "estamos num bairro tradicional de Buenos Aires, em um daqueles cafés antigos com janela de vitrais na porta" e "parecido com o de O Filho da Noiva", em que os Atributos circunstanciais "num bairro tradicional de Buenos Aires" e "em um daqueles cafés antigos com janela de vitrais na porta" indicam o lugar onde o enredo do filme acontece e alguns detalhes desse lugar. Os epítetos "tradicional" e "antigos" evidenciam atitudes positivas de apreciação do tipo valoração, que são avaliações do autor do texto em relação ao local onde o enredo do filme acontece.

O local exato é evidenciado pela oração existencial "Lá dentro há uma mesa de pebolim". A personagem principal do filme é representada na oração relacional identificadora "O campeão inconteste é o jovem introvertido Amadeo". Os epítetos "inconteste", "jovem" e "introvertido" expressam atitudes positivas de apreciação e julgamento: o primeiro é uma avaliação positiva de apreciação do tipo reação/qualidade, o segundo é uma avaliação também de apreciação do tipo valoração, e a terceiro, uma avaliação de julgamento de estima social do tipo normalidade.

Finalizando a etapa Descrição, mais uma personagem é introduzida na descrição do filme: o rival de Amadeo. Na oração material "Anos depois de derrotar no jogo o garoto mais metido da vizinhança", o epíteto "metido" evidencia atitude negativa de julgamento de estima social do tipo normalidade, que é uma avaliação do autor do texto em relação ao rival de Amadeo. 
O problema principal vivenciado por Amadeo no filme é indicado ao(s) leitor(es) por meio da oração mental "Amadeo vê o rival", seguida da oração material "retornar à cidade, agora como um astro mundial do futebol de campo", da oração mental "determinado a destruir o café e a mesa de pebolim" e novamente de uma oração material "construir no lugar um gigantesco estádio para uso próprio". Além disso, é possível evidenciar mais uma avaliação do autor em relação à construção do rival de Amadeo. Isso pode ser observado por meio do sintagma preposicionado "como um astro mundial do futebol de campo", que realizam atitude positiva de apreciação do tipo valoração.

\subsubsection{Etapa Julgamento do Texto}

$\mathrm{Na}$ etapa Julgamento do texto, o autor do texto faz amplo uso de avaliações de atitude dos campos semânticos julgamento e apreciação para expressar sua opinião em relação à construção das personagens, das cenas de ação do filme e do filme como um todo.

Não deixa de ser irônico || ver o longa de Campanella, com sua posição contrária à mercantilização, || estrear no Brasil em meio às polêmicas de superfaturamento das obras da Copa do Mundo, || mas de qualquer forma Um Time Show de Bola é o tipo de história atemporal como toda peça de nostalgia: numa equipe os mercenários e oportunistas, na outra os defensores de tradições (de família, de cultura).

No início da etapa, na oração relacional "Não deixa de ser irônico", o Atributo "irônico" indica uma avaliação negativa de apreciação do tipo reação/impacto, em que o avaliado é a oração mental "ver o longa de Campanella, com sua posição contrária à mercantilização". Após, mediante a escolha do epíteto "atemporal", do classificador "de nostalgia" e dos núcleos de grupo nominal "mercenários" "oportunistas" e "defensores da tradição", todos presentes na oração relacional "Um Time Show de Bola é o tipo de história atemporal como toda peça de nostalgia: numa equipe os mercenários e oportunistas, na outra os defensores de tradições (de família, de cultura)", observam-se avaliações positivas de apreciação do tipo valoração no epíteto "atemporal" em relação ao referente "história" e no classificador "de nostalgia" em relação a "peça". Os dois núcleos de grupo nominal remetem essas avaliações ao texto que está sendo avaliado, no caso, o filme.

Encerrando esse trecho, dois tipos de avaliações em relação às personagens são usados: os grupos nominais "os mercenários e oportunistas", pelos quais o rival de Amadeo e componentes de sua equipe são avaliados negativamente com atitudes de julgamento de sanção social do tipo propriedade, em contraponto a Amadeo e seus amigos, que são avaliados positivamente com atitude de julgamento também de sanção social do tipo propriedade, por meio do grupo nominal "os defensores da tradição".

Continuando a avaliação das personagens, o autor faz uso de orações relacionais e materiais, além de uma oração existencial e uma mental.

Se Amadeo, seu rival e os demais personagens humanos são pobremente desenvolvidos, || em parte é porque têm dificuldade [[[[de fugir desses papéis]] que lhes reservaram]]. || (E desenhar personagens com olhos gigantes || para forçar na emotividade || é um cacoete de animação dos mais baratos). || A grande graça do filme são os jogadores do pebolim, || que ganham vida || para ajudar Amadeo em sua aventura. || Esses, sim, têm personalidade, || embora algumas das piadas façam mais sentido para os argentinos do que para os brasileiros, como a do atacante "Sansão" que perde seu grande trunfo, a cabeleira.

Nesse excerto, o Atributo "pobremente desenvolvidos" evidencia uma avaliação negativa de apreciação do tipo reação/qualidade em relação a "Amadeo, seu rival e os demais

Revista do GELNE, Natal/RN, Vol. 21 - Número 2: p. 3-17. 2019 
personagens humanos". A oração relacional atributiva "têm dificuldade de fugir desses papéis" evidencia uma avaliação negativa de julgamento de estima social do tipo incapacidade. Entre parênteses, a oração material "desenhar personagens com olhos gigantes" é avaliada de forma negativa pelo Atributo "um cacoete de animação dos mais baratos".

Em contraponto, "os jogadores de pebolim" são avaliados positivamente por meio do Atributo "a grande graça do filme", que evidencia apreciação do tipo reação/impacto, e da oração relacional atributiva "têm personalidade", que expressa julgamento de estima social do tipo tenacidade.

No excerto a seguir, encerrando a etapa Julgamento e, consequentemente o texto, o autor faz amplo uso de avaliações positivas de apreciação em relação aos jogadores de pebolim, às cenas de ação do filme e ao próprio filme como um todo:

Para usar um chavão de boleiro, || os personagens-jogadores mostram ter entrosamento suficiente | | para carregar o filme, || e Campanella filma as cenas de ação com a mesma virtuose, em planos sem cortes, | que ele havia mostrado justamente na cena de futebol de seu O Segredo dos Seus Olhos. || No mais, há sempre um charme muito particular nessas animações de aventureiros em miniatura de Toy Story a Pequenos Guerreiros - || e Um Time Show de Bola se esforça || para se filiar a essa linhagem. || Só não precisava pesar tanto a mão nos olhos gigantes...

Em relação aos personagens-jogadores, o autor utiliza apreciação positiva do tipo reação/qualidade, realizada pela oração relacional atributiva "mostram ter entrosamento suficiente".

Em relação às cenas de ação, mais apreciação positiva do tipo reação/qualidade é evidenciada pela Circunstância de modo "com a mesma virtuose" na oração "Campanella filma as cenas de ação com a mesma virtuose, em planos sem cortes".

Por fim, na oração existencial "No mais, há sempre um charme muito particular nessas animações de aventureiros em miniatura - de Toy Story a Pequenos Guerreiros", uma apreciação positiva é expressa pelo Existente "um charme muito particular". Essa avaliação, que é do tipo valoração, tem como item avaliado a circunstância de localização "nessas animações de aventureiros de miniatura - de Toy Story a Pequenos Guerreiros", pela qual o autor avalia não só o filme em questão, como também outras animações mais. $\mathrm{Na}$ oração "Um Time Show de Bola se esforça para se filiar a essa linhagem", por meio do processo comportamental "se esforça", o autor avalia o filme no todo, por meio da apreciação positiva do tipo reação/qualidade.

\subsection{Instanciação do gênero de texto interpretação temática no texto intitulado Filme propõe um olhar amoroso, mas não idealizado}

No texto utilizado em atividades de produção de textos no $2^{\circ}$ ano do ensino médio, as análises evidenciaram a instanciação do gênero de texto interpretação temática, em que a EEG está organizada nas etapas Apresentação dos elementos ${ }^{\wedge}$ Avaliação dos elementos ${ }^{\wedge}$ Reiteração do tema. A seguir, são apresentadas as análises que evidenciam a realização das etapas.

\subsubsection{Etapa Apresentação dos elementos}

A etapa de abertura da interpretação temática em questão é realizada por orações relacionais, materiais e uma oração mental, que apresentam o tema e os elementos a serem avaliados. 
Cao Hamburger pensou a saga da criação do Parque Nacional do Xingu || da maneira como foi resultado de idealismo e do sentimento de aventura. | Qualidades, aliás, que se foram erodindo com o tempo || até caírem de moda, pelo menos no plano prático. || Nos discursos vazios, continuam sendo palavras nobres.

A etapa inicia com a apresentação do filme, realizado como Fenômeno "a saga da criação do Parque Nacional do Xingu" na oração mental "Cao Hamburger pensou a saga da criação do Parque Nacional do Xingu". Assim como a etapa Contexto do gênero de texto resenha, o nome ou título do objeto a ser avaliado não é revelado. Nesta interpretação temática, apenas o tema é apresentado.

Em seguida, são apresentados os elementos que serão objeto de sinopse e avaliação na etapa posterior. Esses elementos são indicados na oração relacional "da maneira como foi resultado de idealismo e do sentimento de aventura", na qual o Atributo "resultado de idealismo e do sentimento de aventura" expressa apreciação positiva do tipo composição/proporção em relação ao Fenômeno "a saga da criação do Parque Nacional do Xingu", que é o tema na etapa. A oração relacional "Nos discursos vazios, continuam sendo palavras nobres" evidencia uma apreciação positiva do tipo valoração, por meio do epíteto "nobres", integrante do grupo nominal "palavras nobres", que remete aos elementos do texto (idealismo e sentimento de aventura) que serão avaliados, novamente, na etapa a seguir.

\subsubsection{Etapa Avaliação dos elementos}

$\mathrm{Na}$ etapa Avaliação dos elementos, concentra-se o maior número de avaliações, por ser a etapa em que os elementos apresentados na etapa anterior são detalhados. Para isso, o autor do texto faz o uso de sinopses do filme para mostrar esses elementos e avaliá-los.

Os irmãos eram de fato aventureiros, || mas nada preocupados [[em amealhar riquezas]]. Era o aspecto humano que os tentava. | No caso, a sobrevivência dos índios no interior de um país [[que já começava a fechar-lhes o cerco]]. Sua missão era basicamente humanística, || no que essa qualidade tem de mais nobre: || respeitar e preservar culturas alheias. ||Mesmo que seja à força: || numa das cenas, uma família é arrancada da sua terra, sob ameaça de arma, || e embarcada rumo ao Xingu. || Se permanecesse || onde queria, || seria dizimada.

Nesse primeiro excerto da etapa, as orações relacionais "Era o aspecto humano que os tentava" e "nada preocupados em amealhar riquezas" remetem ao elemento idealismo, objeto de sinopse neste primeiro momento. A segunda oração expressa julgamento positivo de sanção social do tipo propriedade em relação aos "irmãos", personagens principais do filme, representados nessas orações relacionais como Portadores de humanidade.

$\mathrm{Na}$ sequência, na oração relacional "Sua missão era basicamente humanística", o Atributo "humanística" expressa apreciação positiva do tipo valoração, em relação ao Portador "sua missão". Após, na oração relacional "no que essa qualidade tem de mais nobre", a missão dos irmãos é avaliada positivamente mais duas vezes para reforçar o idealismo das personagens principais: por meio do Portador "essa qualidade" e do Atributo "mais nobre", ambos indicando apreciação do tipo valoração.

O idealismo é especificado em "respeitar e preservar culturas alheias. Mesmo que seja a força”. Para exemplificar o uso da força, o autor utiliza uma sequência de orações materiais: "numa das cenas, uma família é arrancada da sua terra, sob ameaça de arma" e "embarcada rumo ao Xingu". A justificativa para uso da força nesse caso é representada por orações em que a referida família é Comportante na oração "Se permanecesse", Experienciador na oração "onde queria" e Existente na oração "seria dizimada". As avaliações usadas nessa breve sinopse indicam 
que o idealismo, conforme é descrito, é um elemento positivo do filme. No excerto subsequente, o elemento "sentimento de aventura" é o objeto de descrição e avaliação.

É bom também [[que os Villas Bôas não sejam apresentados como seres perfeitos]]. || Cada um deles é visto em suas contradições. Leonardo (Caio Blat) com sua fraqueza e o envolvimento com uma índia; Cláudio (João Miguel) com suas incertezas, || o que faz dele o personagem mais complexo, muito por mérito do ator; || Orlando (Felipe Camargo), com seu senso prático obstinado. || Há conflitos entre os irmãos. || Leonardo é o alijado do grupo. || Cláudio acusa Orlando de excessiva flexibilidade política; || este lhe responde || que, sem negociar, nada conseguiriam. || É verdade. || Tanto é assim || que obtém a assinatura do decreto [[que cria o Parque Nacional do Xingu]] do mais improvável dos personagens, Jânio Quadros, em sua breve e desastrada presidência.

Ao usar as orações relacionais "É bom também que os Villas Bôas não sejam apresentados como seres perfeitos" e "Cada um deles é visto em suas contradições", o autor do texto introduz um contraponto com a positividade apresentada na avaliação do elemento anterior. O Atributo "bom" indica a opinião favorável do autor com relação à representação de imperfeição dos personagens. A partir daí, destaca características pontuais de cada personagem por meio de Atributos circunstanciais que expressam julgamentos de não tenacidade ("com sua fraqueza"), de normalidade ("com suas incertezas" e "o alijado"), tenacidade ("com seu senso prático obstinado") e propriedade ("flexibilidade política", intensificada por "excessiva").

Assim como no excerto anterior, depois de diversas avaliações, o elemento objeto de sinopse é especificado. Para isso, o ator utiliza, em sequência, diversas orações para exemplificar o sentimento de aventura das personagens: as orações verbais "Cláudio acusam Orlando de excessiva flexibilidade política" e "este lhe responde"; as orações relacionais "É verdade [sem negociar, nada conseguiriam]" e "Tanto é assim"; a oração material "obtém a assinatura do decreto que cria o Parque Nacional do Xingu do mais improvável dos personagens, em sua breve e desastrada presidência". O epíteto "improvável" expressa apreciação negativa de reação/impacto em relação a "Jânio Quadros", e "breve" e "desastrada" expressam, respectivamente, apreciação de composição/proporção e composição/qualidade em relação à "presidência" de Jânio Quadros.

No próximo excerto, que ainda pertence a etapa Avaliação dos elementos, a avaliação do elemento "sentimento de aventura" continua, embora as personagens que servem de apoio à sinopse desse elemento não sejam mais as personagens principais.

E há os índios, seu meio ambiente, seu modo de ser, || que se tornam, de fato, os personagens maiores deste filme amoroso, || mas nada piegas e nem cultor do mito do bom selvagem. || A natureza é tanto sedutora quanto hostil. || As relações humanas, tão fraternas quanto ásperas em algumas passagens. || E, do todo, fica a sensação desolada [[de que, no encontro entre duas culturas, | | sendo uma muito mais predatória que a outra ||, uma delas tende a sucumbir]].

Para ilustrar as aventuras vividas pelas personagens principais, novas personagens são introduzidas por meio da oração existencial "há os índios, seu meio ambiente, seu modo de ser". Os índios são identificados como "os personagens maiores deste filme amoroso", que expressa avaliação positiva de apreciação do tipo valoração. Já o epíteto "amoroso" avalia o núcleo do seu grupo nominal, que é "filme".

Ainda descrevendo aspectos do filme que servem de apoio às aventuras vividas pelas personagens, o autor mostra aspectos paradoxais da "natureza" e das "relações humanas". A natureza é avaliada positivamente por meio do Atributo "sedutora" e negativamente por meio do Atributo "hostil". Seguindo a mesma lógica, as relações humanas são avaliadas positivamente por meio do Atributo "fraternas" e negativamente por "ásperas". Ao final da etapa, o autor faz uma 
reflexão sobre essas aventuras, evidenciada nas orações existenciais "E, do todo, fica a sensação desolada" e "no encontro entre duas culturas, uma delas tende a sucumbir". O motivo da sucumbência é representado pela oração relacional atributiva "sendo uma muito mais predatória que a outra".

Nessas orações, também se evidencia a realização de avaliações de afeto e julgamento. Avaliação de afeto do tipo infelicidade é expressa por "sensação desolada", e o gatilho da avaliação é a oração relacional "no encontro entre duas culturas, uma delas tende a sucumbir". $\mathrm{Na}$ oração relacional "sendo uma mais predatória que a outra", verificam-se dois julgamentos negativos: um de sanção social do tipo propriedade, uma vez que um dos avaliados é a cultura do homem branco, que invade as terras indígenas atrás de dinheiro, e outro de estima social do tipo capacidade, já que os índios têm pouco artifícios para lutar contra os homens brancos, que tomam suas terras.

A partir dessas análises, é possível comparar essa etapa como a etapa Descrição do texto analisado na subseção anterior. Lá, a Descrição do texto é curta e o número de avaliações é pequena. Aqui, a etapa é consideravelmente maior e o número de avaliações que se realizam na etapa também. Lá, as poucas avaliações na etapa caracterizam as personagens e o lugar onde o enredo do filme se passa. Aqui, embora haja um amplo uso de avaliações sobre personagens e o ambiente onde se passa o enredo, essas avaliações servem de apoio para a avaliação dos elementos do filme.

\subsubsection{Etapa Reiteração do tema}

Encerrando o texto, o reconhecimento da etapa Reiteração do tema também ajuda a diferenciar o gênero de texto interpretação temática do gênero de texto resenha. No texto em análise, o autor utiliza orações relacionais e uma oração material para reiterar o tema do filme, mas de forma avaliativa:

Xingu descreve esse ato heroico de preservação, sempre precário, sempre provisório, felizmente contra a lógica do mais forte. || Essa disposição [[de lutar contra as evidências]] é o grande legado dos Villas Bôas.

$\mathrm{Na}$ oração material que inicia a etapa, a Meta "esse ato heroico de preservação" realiza apreciação positiva do tipo valoração em relação ao Ator "Xingu", que é uma referência ao filme que conta "a saga da criação do Parque Nacional do Xingu", mencionada na etapa Apresentação dos elementos. Depois da reiteração do tema, o mesmo é objeto de avaliação, como observado nos epítetos "precário", e "provisório", que realizam avaliações negativas de apreciação do tipo composição/qualidade.

Por fim, as avaliações de afeto e apreciação resumem a reação positiva do autor ao filme cujos elementos foram anteriormente apresentados. O Adjunto de comentário "felizmente" expressa afeto do tipo felicidade, na qual o gatilho da avaliação é a Meta "esse ato heroico de preservação". A oração relacional que encerra o texto identifica a "disposição de lutar contra as evidências "como "o grande legado dos Villas Bôas", grupo nominal que expressa apreciação positiva do tipo valoração.

\section{CONSIDERAÇÕES FINAIS}

A partir da análise do sistema de Transitividade e do subsistema atitude da Avaliatividade, foi possível evidenciar que os dois textos possuem propósitos sociocomunicativos específicos diferentes, o que permite concluir que instanciam gêneros de texto na perspectiva da LSF. O texto selecionado do LDLP mais distribuído para o oitavo ano do ensino fundamental instancia o gênero de texto resenha, com a EEG organizada nas etapas Contexto ${ }^{\wedge}$ Descrição ${ }^{\wedge}$ 
Julgamento; o texto selecionado do LDLP mais distribuído para o segundo ano do ensino médio instancia o gênero de texto interpretação temática e sua EEG está nas organizada nas etapas Apresentação dos elementos ^ Avaliação dos elementos ^ Reiteração dos elementos.

É interessante destacar que os textos analisados neste trabalho são bastante semelhantes no que diz respeito ao amplo uso de orações relacionais para descrever personagens, lugares, aspectos do texto que está sendo avaliado, e realizações de julgamento e apreciação. Também é plausível destacar que a diferença entre esses gêneros de texto é bastante sutil e detectar essa diferença requer uma análise detalhada, que nos leva a concluir que a diferença entre os textos é a abstração: de acordo com Christie e Derewianka (2008), em uma escala entre mais complexo e menos complexo, o gênero de texto interpretação temática é mais complexo que o gênero de texto resenha, pois envolve mais abstração. Isso pôde ser confirmado em nossas análises.

Para estudos futuros, destacamos que é relevante ampliar o corpus para confirmar as análises aqui apresentadas. Também sugerimos a inclusão de outros sistemas léxico-gramaticais e semântico-discursivos (MARTIN; ROSE, 2007), para que se tenha um maior arcabouço linguístico no ensino de gêneros de texto da família de reações a texto.

Espera-se, assim, que as análises apresentadas oportunizem o ensino dos gêneros de texto resenha e interpretação temática a partir das suas características linguísticas. Mais precisamente, espera-se que as análises empreendidas neste estudo possam ser utilizadas em atividades do Ciclo de Ensino e Aprendizagem de Gêneros, que é a metodologia utilizada pela LSF para ensinar os gêneros de texto e as características linguísticas que as realizam.

\section{REFERÊNCIAS BIBLIOGRÁFICAS}

BRASIL. Ministério da Educação. Secretaria de Educação Fundamental. Parâmetros Curriculares Nacionais: Língua Portuguesa. Brasília: MEC/SEF, 1998.

CAMPOS, Maria Tereza Aparecida et al. Português - Vožes do mundo 1: literatura, língua e produção de texto. 1. ed. São Paulo: Saraiva, 2013.

CEREJA, William; MAGALHÃES, Thereza Cochar. Português linguagens - $8^{\circ}$ ano. 9. ed. São Paulo: Saraiva, 2013a.

Paulo: Saraiva, 2013b. . Português linguagens - Volume 1. 9. ed. São Português linguagens - Volume 2. 9. ed. São

Paulo: Saraiva, 2013c. Português linguagens - Volume 3. 9. ed. São

Paulo: Saraiva, 2013d.

CHRISTIE, Frances; DEREWIANKA, Beverly. School Discourse: Learning to Write Across the Years of Schooling. London: Continnum, 2008.

EGGINS, Susanne. An introduction to systemic functional grammar. 1. ed. London: Printer Publishers, 1994.

; MARTIN, James Robert. Genres and Registers of Discourse. In: VAN DIJK, Teun Adrianus. (Org.). Discourse as Structure and Process. London: SAGE, 1997. 
IEDEMA, Rick; et. al. Media Literacy. 1. ed. New South Wales: Metropolitan East Disadvantaged Schools Program, 1994.

FERREIRA, A.B.H. Dicionário da língua portuguesa. 5. ed. Curitiba: Positivo, 2010.

FNDE. Dados estatísticos. Disponível em: https://www.fnde.gov.br/programas/programas-dolivro/livro-didatico/dados-estatisticos. Acesso em: 29 de nov. 2018.

GERHARDT, Carla Carine. Investigações dos gêneros episódio e exemplum na perspectiva sistêmico-funcional em livros didáticos de língua portuguesa do ensino fundamental. $234 \mathrm{f}$. Dissertação (Mestrado em Letras) Universidade Federal de Santa Maria, 2017.

HALLIDAY, Michael Alexander Kirkwood. Parte A. In: HALLIDAY, Michael Alexander Kirkwood; HASAN, Ruqaiya. Language, context, and text. aspects of language in a social-semiotic perspective. Oxford: Oxford University Press, 1985.

\section{Halliday's Introduction to}

Functional Grammar. 4. ed. Milton Park, Abingdon, Oxon: Routledge, 2014.

LEMKE, Jay. Textual Politics: discourse and social dynamics. 1. ed. London: Taylor \& Francis, 1995.

MARTIN, James Robert. English Text. System and Structure. Amsterdam: Benjamins, 1992. Analysing genre: functional parameters. In: CHRISTIE, Frances;

MARTIN, James Robert. Genre and instituitions. Social Process in the workplace and school. 1. ed. London, Continnum, 1997.

; WHITE, Peter Robert. The language of evaluation: appraisal in English.

Nova York, Hampshire: Palgrave Macmillan, 2005.

London: Continuum, 2007.

; ROSE, David. Working with discourse - Meaning beyond the clause. 2. ed.

; Genre Relations: Mapping Culture. London: Equinox, 2008.

MELO, Barbara Olímpia Ramos de. Gêneros textuais e argumentação: propostas de ensino do artigo de opinião em livros didáticos. Linha D'Água, v. 28, n. 2, p. 67-84, 1 dez. 2015.

NASCIMENTO, Teresinha de Jesus Gomes do. Estudo do gênero: abordagem de estilo no livro didático de língua portuguesa do ensino médio. 123 f. Dissertação (Mestrado em Linguística) Universidade Federal da Paraíba, 2016.

ROSE, David; MARTIN, James Robert. Learning to Write, Reading to Learn: Genre, Knowledge and Pedagogy in the Sydney School. London: Equinox, 2012.

SOARES, Rosana Muniz. Gêneros em contos e crônicas em livros didáticos de português no ensino médio: um estudo sistêmico-funcional. 438 f. Tese (Doutorado em Linguística) - Universidade de Brasília, 2018.

THOMPSON, Geoff. Introducing Functional Grammar. London: Arnold, 2004.

Submetido em 30/11/2018

Aceito em 21/05/2019

Publicado em 04/07/2019 